\title{
Combustion characteristics of a spark-ignited split-cycle engine fuelled with methane
}

\begin{abstract}
This paper begins with a brief introduction to the operating principles of a split-cycle engine that utilizes a valved, intermediary volume to connect the two engine cylinders. Results from experimental testing of the engine fueled with pure methane are presented with a particular emphasis on the combustion duration and phasing. Two different methods of analysing the combustion duration - the mass fraction burn (MFB) and normalized pressure ratio (PRN) - are given. Testing was performed at wide open throttle (WOT) for engine speeds ranging from 850-1200 rpm, and air-fuel equivalence ratios from 0.8-1.0. The results indicate that the main combustion duration is very rapid for all conditions tested, despite late combustion phasing. Changes in spark timing were shown to have a considerable impact on IMEP but did not greatly effect the burn duration. Cyclic variability of IMEP was found to be less than $4 \%$ for all cases, except when operation was leaner than $\varnothing=0.85$, indicating good combustion stability.
\end{abstract}

Key words: spark ignition engines, split-cycle, methane, natural gas, CNG, fast burn, turbulence

\section{Introduction}

The use of natural gas (NG) as a transportation fuel is supported by many appealing attributes associated with the fuel's properties and the resulting combustion characteristics. The fuel is primarily composed of methane, generally $>90 \%$ by volume, which provides excellent knock resistance and the ability to employ higher engine compression ratios. Furthermore, NG is often referred to as a clean-burning fuel, which stems from the low levels of combustion product pollutants. In comparative engine trials between gasoline and NG, Evans and Blaszczyk [1] report lower $\mathrm{HC}$ and $\mathrm{CO}$ emissions for the majority of conditions tested under NG fuelling, and up to $50 \%$ less at certain full load conditions. $\mathrm{NO}_{x}$ emissions, however, are generally on par with gasoline fuelled engines, or slightly higher due to the advanced timing required for the slower combustion of NG. Greenhouse gas emissions are also inherently lower on account of a relatively low carbon-to-hydrogen ratio. Interested readers can find a comprehensive review of $\mathrm{NG}$ engine performance and emissions characteristics in Cho and He [2], as well as Semin [3] and Korakianitis et al. [4].

Despite the many benefits of using NG as an alternative fuel for internal combustion engines, several obstacles remain to be overcome. Storage and durability issues, for example, are problematic due to the fuel's low density and lack of lubricity, respectively. For port injected engines, the fuel density is also destructive to the volumetric efficiency by as much as $10-15 \%$ [2], as the fuel displaces a large portion of intake air. From a combustion stand-point, $\mathrm{NG}$ is also disadvantaged by its low laminar flame speed, which results in a relatively lengthy combustion duration. Consequently, MBT spark timing must be advanced in comparison to gasoline operation - up to $10^{\circ} \mathrm{CA}$ under certain conditions [1] - leading to increased pumping work and higher heat transfer losses.

It is well documented that turbulent fluid motion within the cylinder can be used to shorten the combustion duration [5-8], and extend the lean limit of NG engine operation
$[9,10]$. The majority of these engines rely on squish volumes and/or specially designed piston cavities to generate turbulence at TDC. This can lead to large flame quenching regions that are prone to producing unburned hydrocarbons. Furthermore, the energy associated with squish-based turbulence is a function of mean piston speed [11] and therefore dependent on engine RPM.

The objective of this research is to evaluate the use of an alternative engine architecture that has potential merit in addressing the issues of volumetric efficiency and combustion duration in NG engines. A split-cycle engine has been developed for this purpose and this paper presents the preliminary combustion characteristics of its operation.

\section{Split-cycle engine operation}

The so-called split-cycle denotes the engine configuration whereby the processes of compression and expansion are segregated into different cylinders. One cylinder performs the intake and compression strokes, while a second cylinder carries out the expansion (combustion) and exhaust strokes. The configuration of fluid transfer from one cylinder to the other is subject to the split-cycle engine designer. In some cases the fluid is directly transferred between cylinders on each and every cycle, controlled by a single valve $[12,13]$. In other scenarios, an intermediary (isobaric) volume exists between the two cylinders [14]. The engine designed for this research uses the latter configuration, for which the intermediary volume will be hereafter referred to as the crossover passage.

To minimize the clearance volume in each cylinder, the valve at each end of the crossover passage opens outward from the cylinder, also known as a reverse poppet valve. This minimizes the amount of trapped mass in the compression cylinder, which otherwise translates into useless pumping work, and also allows for the valve on the outlet side of the crossover passage to be open while the piston is in the vicinity of TDC.

Opening and closing of the valves are timed such that the crossover passage remains (ideally) in an isobaric state. 
In reference to the P-V diagrams shown in Figs 1 and 2, the split-cycle process is as follows:

Compression cylinder process (Fig. 1):

1-2 The intake valve closes and compression of air begins.

2-3 At 2 the cylinder pressure has reached the crossover pressure and the inlet crossover valve opens. As the compression stroke continues, the air in the cylinder is transferred into the crossover passage.

3-4 The crossover inlet valve closes and cylinder residuals are expanded to atmospheric pressure.

4-1 The intake valve opens and fresh air is brought into the cylinder for the repeating cycle.

Expansion cylinder process (Fig. 2):

1-2 The exhaust valve opens and combustion products are expelled from the cylinder.

2-3 Approximately $10{ }^{\circ} \mathrm{CA}$ before TDC the exhaust valve closes while the crossover outlet valve simultaneously opens. Typically, fuel would be admitted at this time, either at the back of the crossover outlet valve or directly into the cylinder. The cylinder is therefore rapidly filled with an air-fuel mixture, in a time frame of several milliseconds. Pressure in the crossover passage remains fairly constant as the exiting mass is being replaced by the phase-lagged compression cylinder.

3-4 Spark initiated combustion and heat release occur after TDC. Spark timing advancement is limited by the closure timing of the crossover outlet valve, to ensure combustion does not propagate back into the crossover passage.

4-1 The combustion products are expanded until exhaust blow-down occurs at (1) and the cycle repeats.

The net indicated work done by the engine is the summation of the integral areas below each PV diagram, with the compression cylinder work having a negative value.

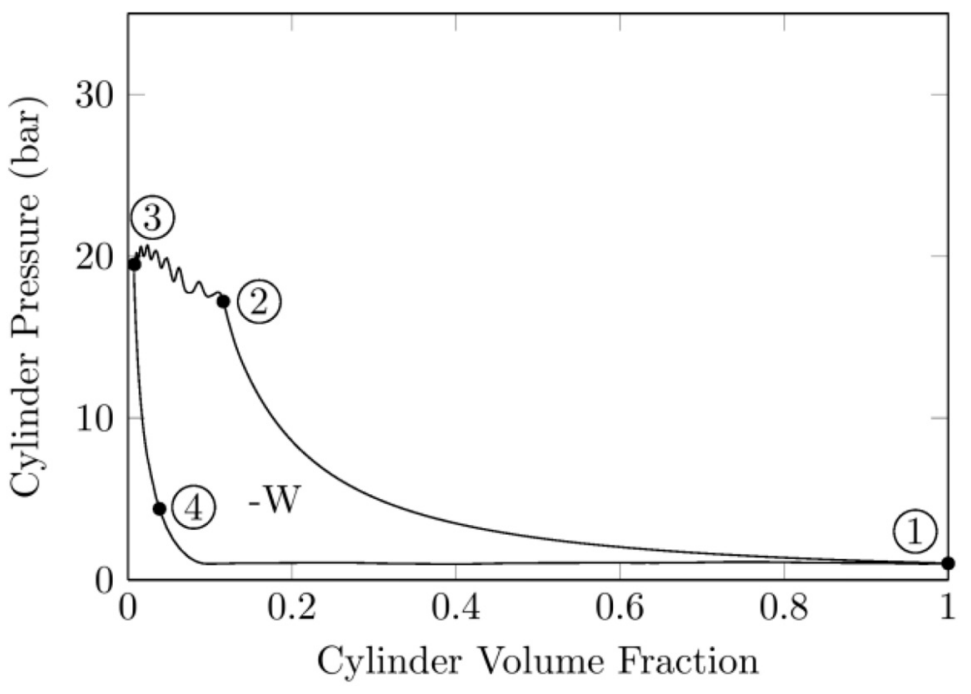

Fig. 1. Example of P-V diagram for compression cylinder

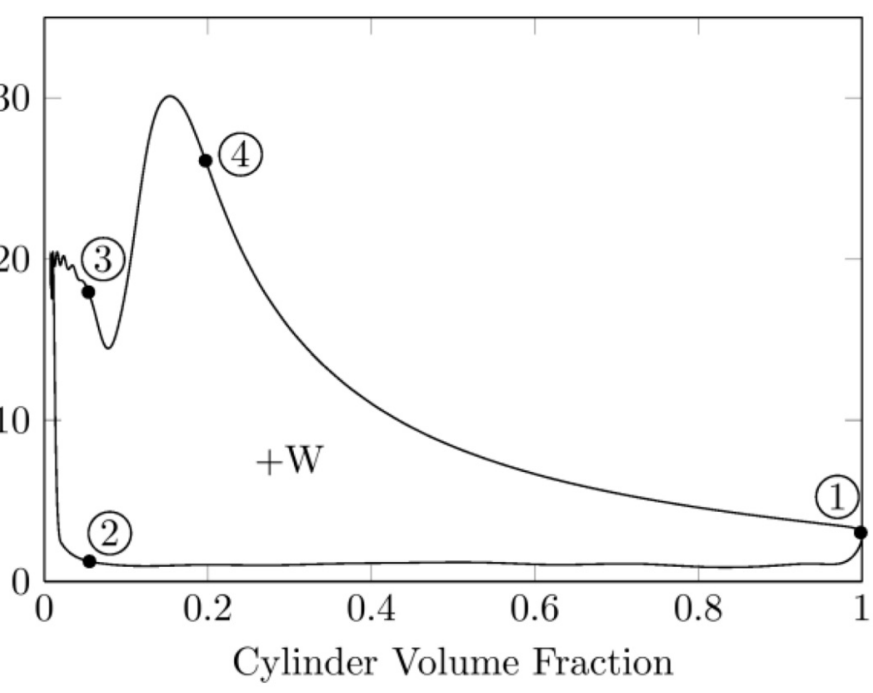

Fig. 2. Example of P-V diagram for expansion cylinder

The pressure ratio between the crossover passage and the expansion cylinder at the time of crossover outlet valve opening (XOVO), is well above the critical value for choked flow conditions. In other words, for the majority of the transfer, the velocity at the inlet boundary to the cylinder is sonic. It is this high velocity, coupled with the small characteristic dimensions of the flow (mainly valve lift height and clearance volume), that generates the small-scale, high-intensity turbulence required for mixing and combustion. Turbulence generation is also largely decoupled from engine speed, which will be discussed in the results section of this paper.

The concept of a split-cycle engine utilizing reverse poppet valves dates back to the early 1900's [15], with many ensuing patents throughout the $19^{\text {th }}$ century $[13,16-18]$. Recently, much attention has been garnered by the Scuderi ${ }^{\text {TM }}$ Group Inc., who have published several articles discussing the development of their split-cycle engine $[14,19,20]$. The interest in determining how split-cycle engine architecture can possibly remedy the short-comings of NG fuelled engines, in terms of poor volumetric efficiency and lengthy combustion duration, were the motivating factors for this research.

\section{Experimental setup}

The split-cycle engine used to carry out the experiments in this work was designed and constructed by the authors at the University of Windsor, and is shown in Fig. 3. It has a two cylinder inline configuration and a displacement of 0.24 liters per cylinder. For sake of simplicity, both cylinders have the same bore/stroke configuration and only minor differences in their TDC volumes to allow for piston clearance from the spark plug and exhaust valve.

The naturally aspirated engine has a single intake and exhaust valve, along with two crossover valves - one for each cylinder. Actuation of the four engine valves is accomplished using 


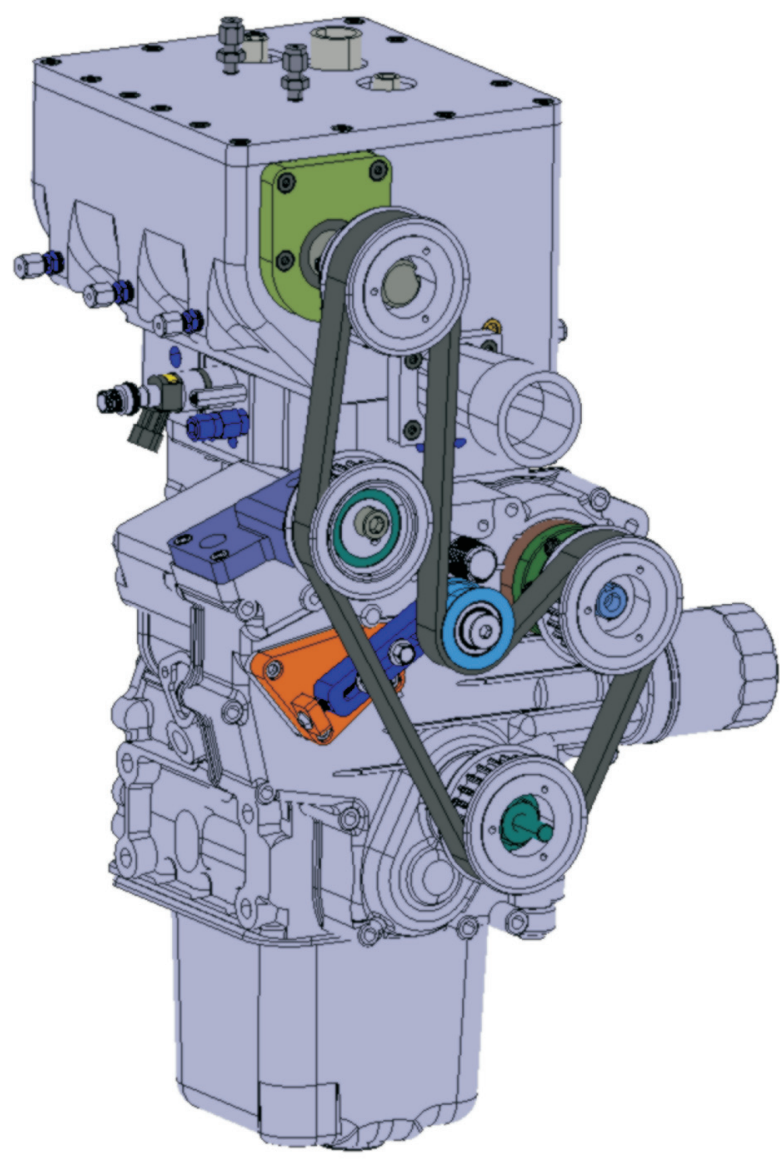

Fig. 3. CAD rendering of split-cycle engine developed by the authors at the University of Windsor

two separate valve trains. The intake and exhaust valve are pushrod driven, while the reverse poppet crossover valves are actuated by an $\mathrm{OHC}$ and a split-finger rocker arm configuration. Both camtrains are driven at a ratio of $1: 1$ by the crankshaft through a synchronous timing belt. Geometric engine specifications are given in Table 1 .

Figure 4 shows the layout of the engine ports, as well as the fuel injector and spark plug locations. The cross-flow design was used to separate the hot exhaust port from the rela-

Table 1. Split-cycle engine geometry

\begin{tabular}{|l|c|}
\hline No. of cylinders & 2 \\
\hline Bore $[\mathrm{mm}]$ & 67 \\
\hline Stroke $[\mathrm{mm}]$ & 68 \\
\hline Connecting rod $[\mathrm{mm}]$ & 98.2 \\
\hline Swept volume $\left[\mathrm{cm}^{3}\right]$ & 240 \\
\hline Crossover volume $\left[\mathrm{cm}^{3}\right]$ & 122.3 \\
\hline Geometric compression ratio & $109: 1$ \\
\hline Geometric expansion ratio & $66: 1$ \\
\hline Crankshaft journal offset & $20^{\circ}$ \\
\hline Intake valve OD [mm] & 25 \\
\hline Exhaust valve OD [mm] & 25 \\
\hline Crossover valve OD [mm] & 19 \\
\hline Int/exh valve lift [mm] & 7 \\
\hline Crossover valve lift [mm] & 3.5 \\
\hline
\end{tabular}

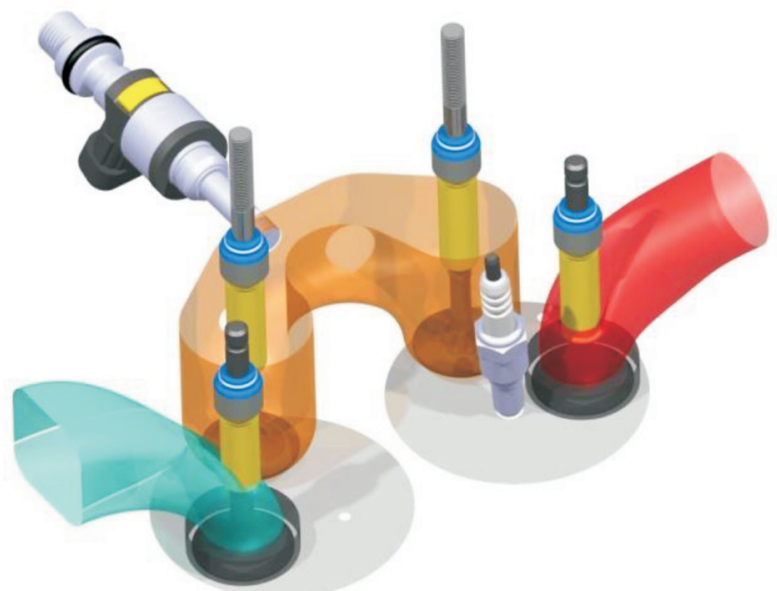

Fig. 4. Split-cycle port configuration: intake (blue), crossover (orange), exhaust (red)

tively cooler compression cylinder. The combustion chamber is pancake- shaped with the exception of a small depression $(\sim 3 \mathrm{~mm})$ to accommodate the spark plug electrode.

Methane fuel is injected directly into the crossover passage from a two-stage pressure regulated bottle. Due to the fuel's high octane rating, autoignition inside the crossover passage is not of concern and allowed for an early injection timing of approximately $260{ }^{\circ} \mathrm{CA}$ before XOVO. At this time, both crossover valves are closed and the residence time inside the crossover passage is used for air/fuel mixing. The fuel spray is also guided to impinge on the convex wall opposing the injector in an effort to break apart the fuel plume and further promote a homogeneous mixture.

By injecting into the crossover passage, the aspiration deficiencies common to port injected $\mathrm{NG}$ engines are eliminated. While the same can be said for direct-injected (in-cylinder) NG systems, the split-cycle has the advantage that combustion does not occur in the crossover passage, reducing the severity of conditions to which the injector is subjected. Furthermore, a lengthy residence time within the crossover passage, coupled with a turbulent discharge period, promotes good mixture homogeneity, which can still be an issue for DI-NG engines [21]. Table 2 provides an overview of the experimental fuel and fuel system properties used in this work.

\section{Instrumentation and data acquisition}

Pressure inside the compression and expansion cylinders was measured using a pair of flush-mounted Kistler 6052C piezoelectric transducers. The crossover passage and intake

Table 2. Fuel \& fuel system specifications

\begin{tabular}{|l|c|}
\hline Fuel composition & $99.99 \%$ methane \\
\hline Octane rating & 130 \\
\hline LHV $[\mathrm{MJ} / \mathrm{kg}]$ & 50 \\
\hline Stoichiometric AFR & 17.16 \\
\hline Fuel pressure [bar] & 69 \\
\hline Injector location & crossover passage \\
\hline Injector type & single-hole GDI \\
\hline Injection timing [ $\left.{ }^{\circ} \mathrm{BTDC}-\mathrm{e}\right]$ & 270 \\
\hline
\end{tabular}


runner were also instrumented with absolute piezo-resistive pressure transducers, Kistler type 4005B and 4043A, respectively. The intake transducer was used to peg the compression cylinder data, while the crossover transducer provided a pegging reference for the expansion cylinder data.

All analog and digital engine data channels were simultaneously sampled at $0.1^{\circ} \mathrm{CA}$ intervals by a National Instruments (NI) 6356, 16-bit DAQ card. All metrics presented in this work were calculated on a single-cycle basis and then averaged. 300 consecutive cycles were used for each operating point. Data processing and logging was performed using NI LabVIEW ${ }^{\mathrm{TM}}$, which, in conjunction with the real-time system of a NI-9074 compact-RIO system, was also used to control fuel injection and spark timing. The mass flow rate of fuel was measured using a Sierra Smart-Trak 100 series thermal mass flow meter. The pressure drop across a calibrated laminar flow element was used to measure the volumetric quantity of air entering the engine and subsequently converted into a mass flow rate with corrections for temperature and humidity. Air-fuel ratios were determined using a wideband $\mathrm{O}_{2}$ sensor in the exhaust header, connected to a Horiba Mexa 730 lambda meter.

The optical encoder used for crank angle measurement was aligned with TDC of the expansion cylinder, and the reader should keep in mind that the compression cylinder TDC occurs $20^{\circ} \mathrm{CA}$ after the expansion cylinder. When applicable, the nomenclature used by Phillips et al. [14] will be adopted here to distinguish between cylinders: indices ' $c$ ' and 'e' represent the compression and expansion cylinders, respectively, when referring to crank angle position (e.g. ATDC-e).

An overview of the engine operating conditions used to acquire the experimental data can be found in Table 3 .

Table 3. Experimental conditions

\begin{tabular}{|c|c|}
\hline Engine speed $[\mathrm{rpm}]$ & $850-1200$ \\
\hline Throttle position $[\%]$ & $100(\mathrm{WOT})$ \\
\hline Coolant temperature $\left[{ }^{\circ} \mathrm{C}\right]$ & 75 \\
\hline Equivalence ratio $[\phi]$ & $0.81-1.0$ \\
\hline Spark timing $\left[{ }^{\circ}\right.$ ATDC-e] & $18-25$ \\
\hline Absolute intake pressure $[\mathrm{bar}]$ & $\sim 1.0$ \\
\hline
\end{tabular}

\section{Experimental results and discussion}

The results presented in this paper are focused on the combustion characteristics of the split-cycle engine: in particular, an assessment of the burn duration and combustion stability. Figure 5 shows the range of net IMEP and RPM values obtained from testing to date.

Figure 6 shows a typical pressure trace of each cylinder together with the crossover passage. Looking at the expansion cylinder trace, it can be seen that upon opening of the crossover outlet valve the cylinder fills very rapidly, generally on the order of 1-2 ms for the engine speeds tested in this work. There is a short dwell period that follows, where the expansion cylinder piston passes through TDC and then begins to recede. The pressure remains fairly constant since the compression cylinder is still finishing its upstroke, and

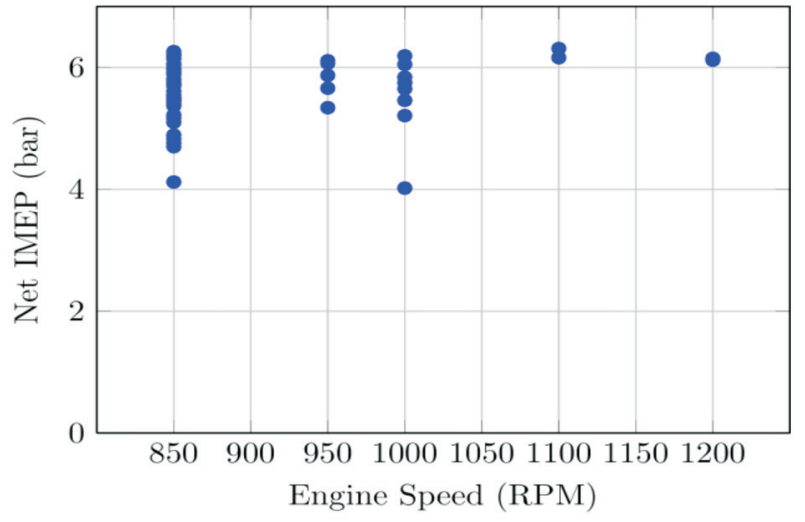

Fig. 5. Engine speed/load combinations tested

since both crossover valves are open, replenishes the outgoing mass. It is worthwhile to note that the minimum volume during this dwell period is located at $10{ }^{\circ} \mathrm{CA}$ ATDC-e, and has been referred to as effective TDC in other work [14].

Spark timing for Fig. 6 is $19{ }^{\circ} \mathrm{CA}$ ATDC-e, which is dictated by two limiting factors: the crossover outlet valve closing (XOVC) time and the peak differential pressure across the XO valve. Since the crossover valves open away from the cylinder, spring preload is used in combination with the crossover passage pressure to maintain valve closure during the peak pressure of combustion. The crossover pressure has a mean value of 18 bar and is relatively constant, with a slight decrease of around 1-1.5 bar over the cycle due to heat transfer and valve seal leakage. At current maximum spring preload conditions, the combined force allows for combustion pressure to exceed that of the crossover passage by roughly 15 bar. Therefore, spark timing advances were limited to the point where the crossover outlet valve was being pushed open by the peak combustion pressure, which was easily detected on the crossover pressure trace. While these occurrences did not result in combustion propagating backwards into the crossover passage, it did reduce the IMEP value for those specific cycles and is further undesirable from a durability viewpoint, since the valve is closed against its seat in an uncontrolled manner after the combustion pressure subsides.

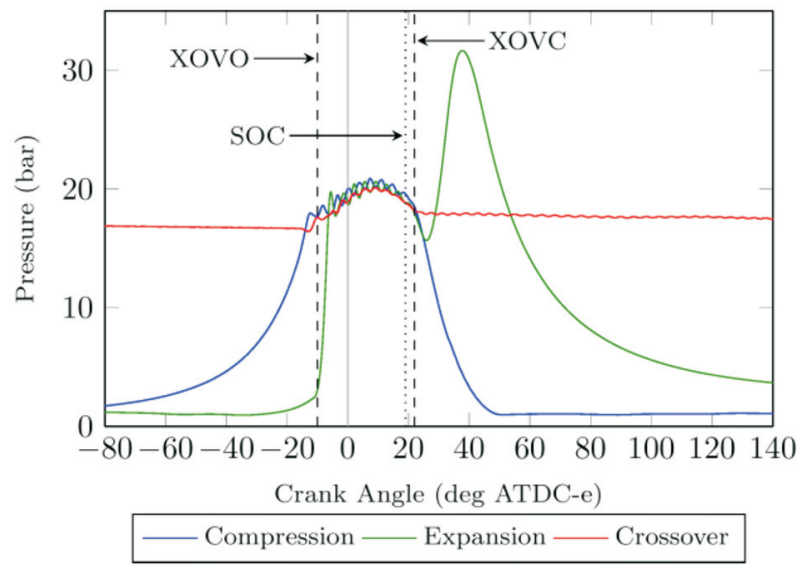

Fig. 6. Cylinders and crossover passage pressure traces of the split-cycle engine at $850 \mathrm{rpm}$, WOT, 19 deg., ATDC-e spark timing, $\varnothing=1$ 
This relatively late spark timing is the reason for the drop in cylinder pressure following TDC. The minimal heat release during the flame development period of combustion allows the cylinder pressure to drop in accordance with the expanding volume. Efforts to advance the combustion phasing are on-going and will be discussed in the future recommendations section at the end of this paper.

\subsection{Burn duration metrics}

Despite its relatively late phase, combustion proceeds very quickly after the flame development period. Figure 7 shows the 300-cycle-averaged MFB curves for two different engine speeds (850 and $1000 \mathrm{rpm}$ ), and for both stoichiometric and lean $(\varnothing=0.85)$ operation. All cases are at WOT

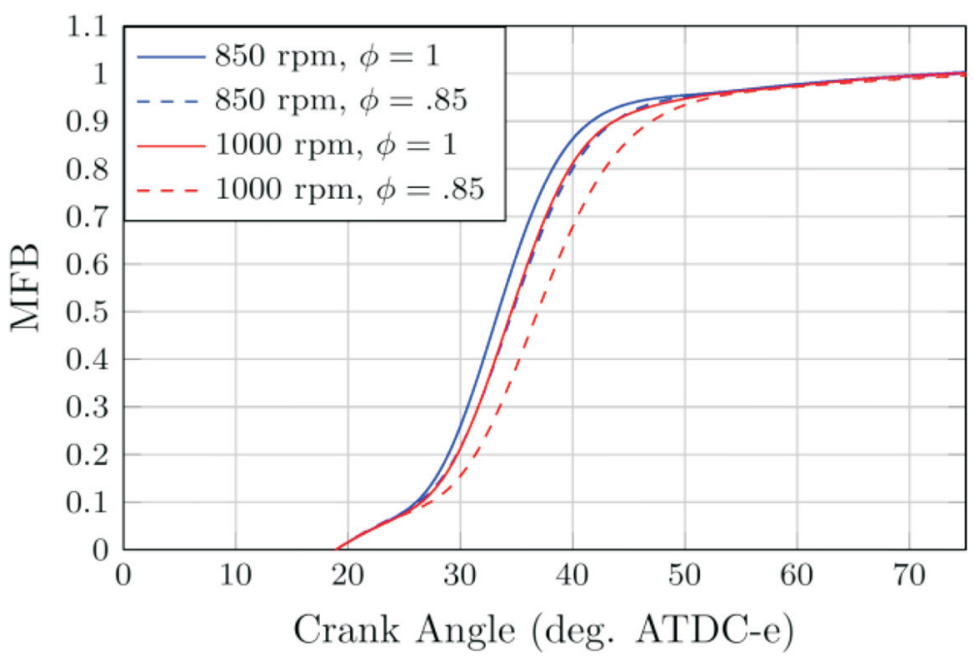

Fig. 7. Example of mass fraction burnt results for two different engine speeds and airfuel equivalence ratios; all cases full load

with a spark timing of 19 deg. ATDC-e. MFB curves were calculated using the modified Rassweiler and Withrow method presented by Ball et al. [22].

Of particular notice is the immediate rise in MFB following the electrical discharge of the spark plug. This is a manifestation of the crossover outlet valve being open during the first $\sim 6^{\circ} \mathrm{CA}$ of combustion. In other words, the expanding volume during this period includes the crossover passage and flow into the cylinder is falsely interpreted as the rise in pressure due to combustion. Regardless, this phenomena only effects the shape of the MFB curve and not the point of combustion completion. Furthermore, the $\mathrm{CA}_{10-90}$ duration is predictably effected in a conservative manner, since the slope of the MFB curve at 0.1 would be steeper if the curves were shifted downwards, reducing the $\mathrm{CA}_{10-90}$ value.

As a secondary metric for analysing combustion duration, the pressure ratio $(\mathrm{PR})$ and its normalized variant $\left(\mathrm{PR}_{\mathrm{N}}\right)$ were calculated according to Eqs. (1) and (2) [23]. Where $\mathrm{P}_{\mathrm{f}}$ and $\mathrm{P}_{\mathrm{m}}$ represent the firing and motoring cylinder pressures at the same engine speed/throttle conditions, respectively. The motoring data used in this work was taken with the engine at operating temperature for improved accuracy.

$$
\begin{gathered}
\operatorname{PR}(\theta)=\frac{P_{f}(\theta)}{P_{m}(\theta)}-1 \\
\operatorname{PR}_{N}(\theta)=\frac{\operatorname{PR}(\theta)}{\max [\operatorname{PR}(\theta)]}
\end{gathered}
$$

A comparison was made between the MFB and PRN curves, as shown in Fig. 8, for a late spark timing of $25^{\circ} \mathrm{CA}$ ATDC-e. Since the crossover outlet valve is fully closed at this spark time, the ambiguity in MFB due to flow entering the cylinder during the early stages of combustion is eliminated.

From Figure 8, it can be seen that the MFB and PRN curves are in close resemblance to one another, with $\mathrm{CA}_{50}$ being almost identical in both cases. The fractional durations $\left(\mathrm{CA}_{10}, \mathrm{CA}_{50}\right.$, etc. $)$ are given in Table 4, which shows the PRN estimate of the $\mathrm{CA}_{10-90}$ burn duration is approximately $3{ }^{\circ} \mathrm{CA}$ faster than that calculated by the MFB equation.

The same data used to plot MFB in Fig. 7 is repotted for PRN in Fig. 9, and the burn duration statistics are given in Table 5. Again, the $\mathrm{CA}_{10 \text { - }}$ ${ }_{90}$ duration is roughly $3-4{ }^{\circ} \mathrm{CA}$ shorter when calculated using PRN versus MFB. The trends with engine speed and equivalence ratio are also consistent between both methods, and therefore the PRN method appears to be a good substitute for MFB in this particular scenario; where flow is entering the cylinder during the early stages of combustion.

\subsection{Combustion progression}

Regardless of the method used to calculate the duration of combustion, it is evident that the

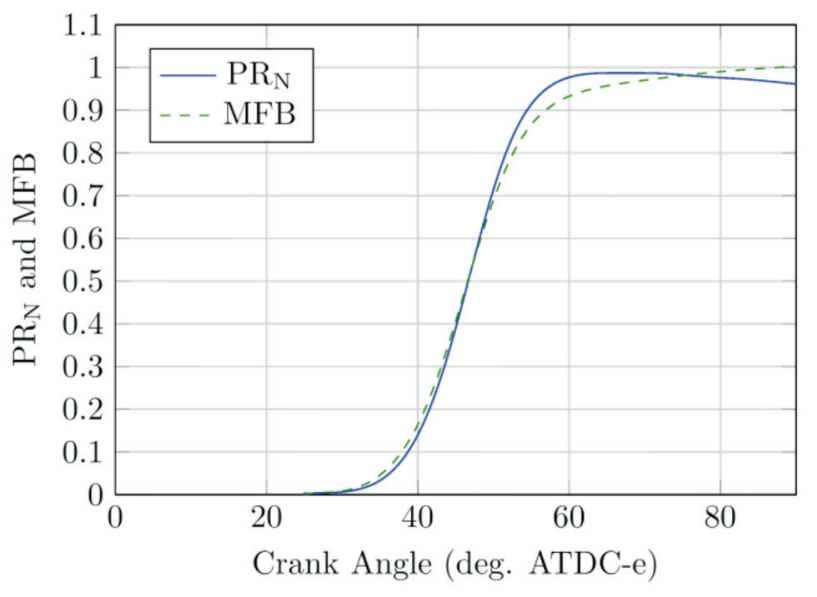

Fig. 8. Comparison of MFB and $\mathrm{PR}_{\mathrm{N}}$ curves

Table 4. Burn duration comparisons between MFB and $\mathrm{PR}_{\mathrm{N}}$; units $={ }^{\circ} \mathrm{CA}$

\begin{tabular}{|c|c|c|c|c|}
\hline & $\mathrm{CA}_{10}$ & $\mathrm{CA}_{50}$ & $\mathrm{CA}_{90}$ & $\mathrm{CA}_{10-90}$ \\
\hline $\mathrm{MFB}$ & 38.7 & 47.1 & 55.6 & 16.9 \\
\hline $\mathrm{PR}_{\mathrm{N}}$ & 39.6 & 47.3 & 53.7 & 14.1 \\
\hline$\Delta$ & -0.9 & -0.2 & 1.9 & 2.8 \\
\hline
\end{tabular}




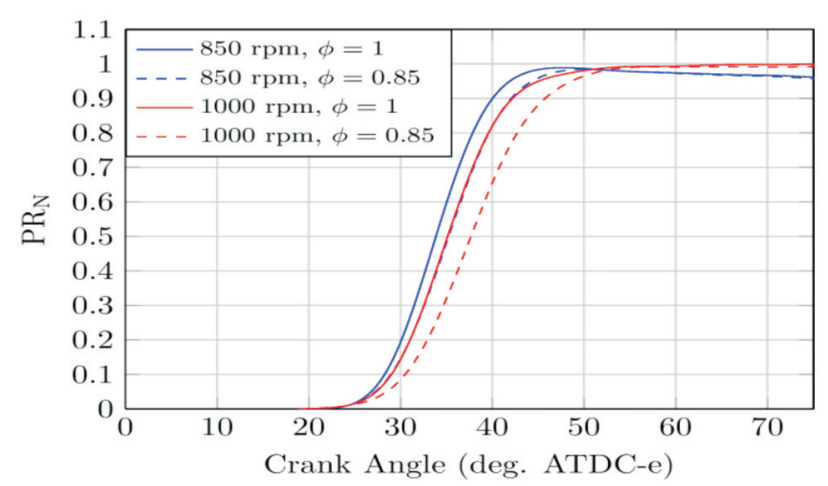

Fig. 9. Normalized pressure ratio vs. crank angle; same data set as Fig. 7

split-cycle engine produces cylinder conditions that are conducive to a fast burn; keeping in mind that there is no squish volume, the mean piston speed is on the order of 2-3 $\mathrm{m} / \mathrm{s}$, and combustion occurs well after TDC. The effects of engine speed, spark timing, and air-fuel ratio will now be explored.

Engine speed effects - it is evident from Figures 7 and 9 that the faster engine speed results in a slightly longer combustion duration in terms of ${ }^{\circ} \mathrm{CA}$. This is consistent with the remaining engine trials up to $1200 \mathrm{rpm}$, as shown in Fig. 10.

Table 5. $\mathrm{CA}_{10-90}$ burn durations for data from Figs 7 and 9 ; units $={ }^{\circ} \mathrm{CA}$

\begin{tabular}{|c|c|c|c|c|}
\hline & \multicolumn{2}{|c|}{$850 \mathrm{rpm}$} & \multicolumn{2}{c|}{$1000 \mathrm{rpm}$} \\
\hline & $\varnothing=1$ & $\varnothing=0.85$ & $\varnothing=1$ & $\varnothing=0.85$ \\
\hline $\mathrm{MFB}$ & 14.9 & 16.2 & 15.4 & 17.8 \\
\hline $\mathrm{PR}_{\mathrm{N}}$ & 11.2 & 12.2 & 12.0 & 13.6 \\
\hline$\Delta$ & 3.7 & 4.0 & 3.4 & 4.2 \\
\hline
\end{tabular}

Both the flame development period $\left(\mathrm{CA}_{0-10}\right)$ and main burn duration $\left(\mathrm{CA}_{10-90}\right)$ exhibit the same trend and roughly follow the observations of Hires et al. [24], who observed these parameters to be proportional to $\mathrm{rpm}^{1 / 3}$. The increased expansion rate at higher engine speed simply offers less time for combustion to be completed.

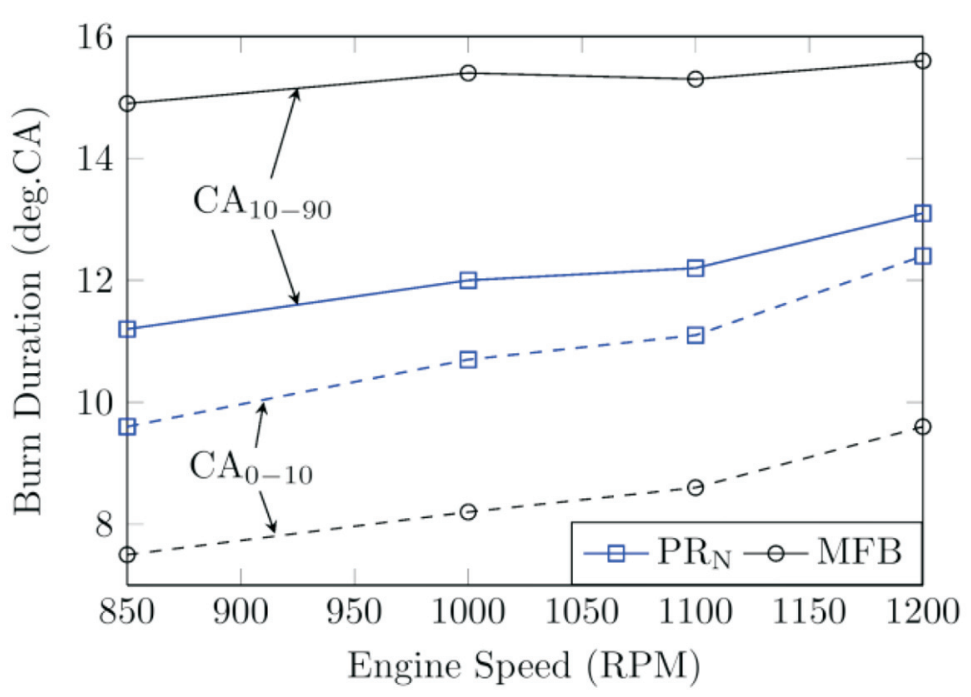

Fig. 10. Effect of engine speed on burn duration
In a standard SI engine, a tradeoff between increased turbulence intensity (roughly equal to $1 / 2$ mean piston speed [25]) and the increasing expansion rate at higher rpm exists. This is not the case for the split-cycle engine used in this work, and begs the question whether or not engine speed and burn duration will scale similar to a conventional SI engine over a broader rpm range. Unfortunately, at this time the split-cycle engine is limited to relatively low speeds $(<1500 \mathrm{rpm})$ due to dynamic constraints imposed by the short-duration valvetrain.

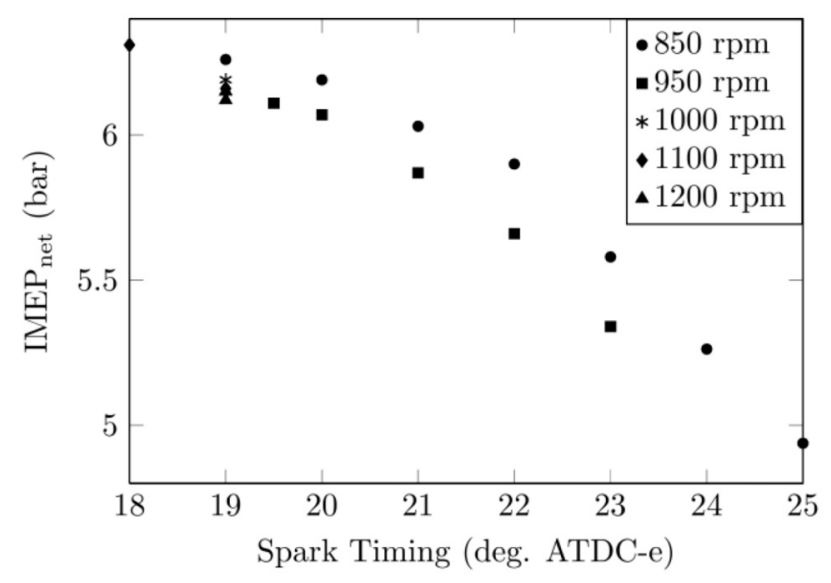

Fig. 11. Net IMEP versus spark timing; WOT, $\varnothing=1$

Spark timing effects - advanced spark timing leads to higher net IMEP of the engine, as shown in Fig. 11, with net IMEP values ranging from 4.8 to 6.3 bar from spark timings of 25 to $18^{\circ} \mathrm{CA}$ ATDC-e, respectively. At this point in time, MBT conditions have not been fully realized due to the limitations associated with the crossover outlet valve, discussed earlier in this paper. The most advanced spark timings presented are at the current limit of operation.

Figure 12 shows the $\mathrm{CA}_{10-90}$ combustion duration over a range of spark timings, from $19-25{ }^{\circ} \mathrm{CA}$ ATDC-e. It is clear that the rate at which combustion progresses is relatively unaffected by spark timing, despite the increase in load (and therefore temperature). The solid lines represent the mean data, while the dashed lines are single-cycle maximum and minimum values for each operating point. There is a very slight trend towards a shorter combustion duration for advanced spark timing: approximately 1.5 to $2.5^{\circ} \mathrm{CA}$ depending on which metric is used for $\mathrm{CA}_{10-90}$. This is thought to be a consequence of the decreasing cylinder pressure, and therefore temperature, at later spark timings, resulting in a slower reaction rate. The trend in IMEP with spark timing is therefore primarily driven by the magnitude and location of peak pressure, and not by any significant changes in combustion or turbulence conditions.

The location of peak pressure (LPP) and $\mathrm{CA}_{50}$ are shown together with IMEP in Fig. 13, for the 


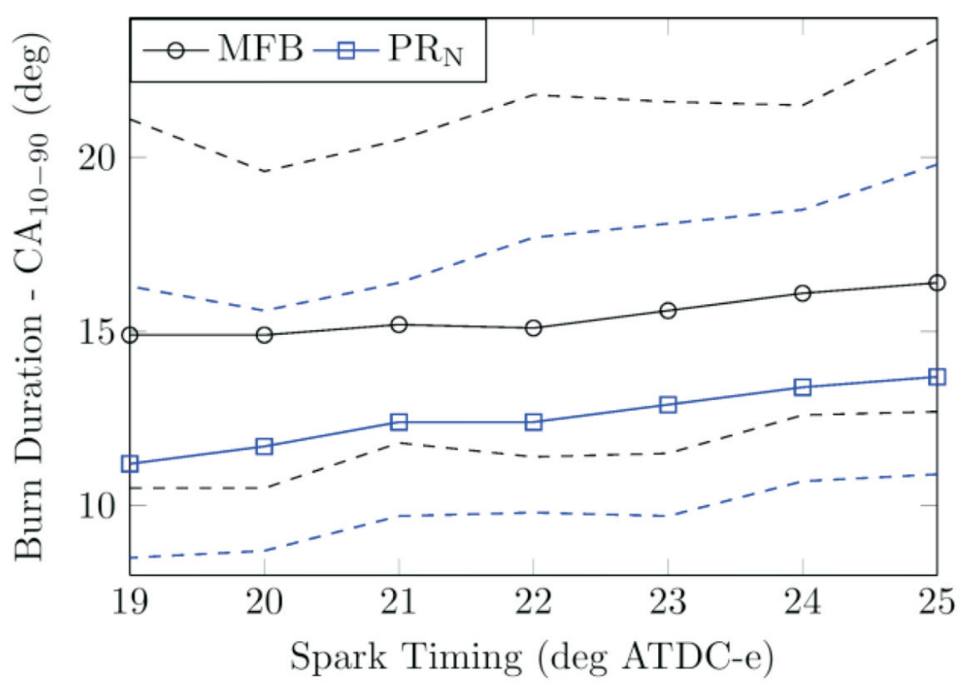

Fig. 12. Burn duration as a function of spark timing; 850 RPM, WOT, $\varnothing=1$ timing, with a slightly decreasing trend towards advanced timing if the point at $19^{\circ} \mathrm{CA}$ is ignored. The variability in burn duration does not appear to effect IMEP, which consistently reduces from 3.4 to $1.5 \%$, as spark is advanced from 25 to 19 ${ }^{\circ} \mathrm{CA}$ ATDC-e.

One possible explanation for the rise in $\mathrm{COV}$ for $\mathrm{CA}_{10-90}$ at $19^{\circ} \mathrm{CA}$, is that the peak pressure in the cylinder will occasionally exceed the closure force of the crossover valve for certain cycles when combustion is very rapid. The opening of the valve occurs at the LPP, which corresponds to a MFB of approximately 0.8 . Therefore, the gases being pushed back into the crossover passage are likely to be combustion products, causing the residuals in the following cycle to be higher. Opening of the crossover valve was detected to occur in approximately $2 \%$ of the cycles for the data shown in Fig. 14 at $19{ }^{\circ} \mathrm{CA}$ spark timing.

same data from Fig. 12. The LPP is inversely correlated with IMEP, and occurs approximately $5{ }^{\circ} \mathrm{CA}$ after the midpoint of combustion $\left(\mathrm{CA}_{50}\right)$. The relationship with LPP and spark timing is non-linear and appears to be reaching a plateau as spark is advanced. This correlates to some degree with cylinder volume, which is changing less rapidly in the vicinity of TDC.

Figure 12 also shows the spread of burn durations present for a given spark timing, with single cycles achieving $\mathrm{CA}_{10-90}$ in as little as 8.5-10.5 ${ }^{\circ} \mathrm{CA}$, to as much as $19.8-23.4{ }^{\circ} \mathrm{CA}$, again depending on the metric used for evaluation. To further investigate the combustion stability, the coefficient of variation (COV) was calculated for the $\mathrm{CA}_{10-90}$ burn durations (both MFB and PRN), as well as the net IMEP. The results are shown in Fig. 14 for an engine speed of $850 \mathrm{rpm}$, and stoichiometric air-fuel ratio. The $\mathrm{COV}$ of $\mathrm{CA}_{10-90}$ is fairly consistent throughout the range of spark

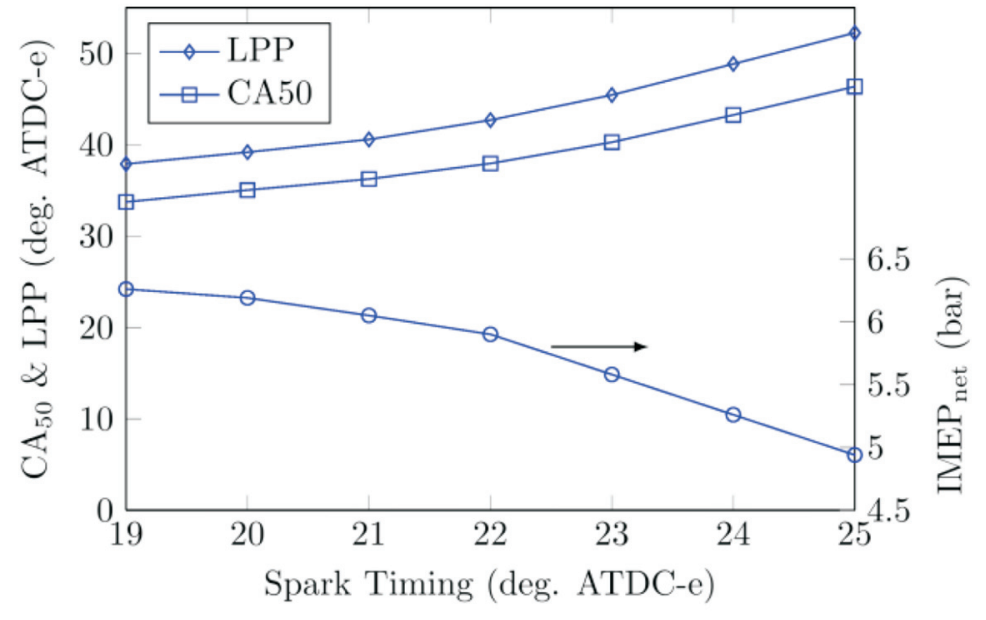

Fig. 13. Effect of spark timing on location of peak pressure and CA50 MFB

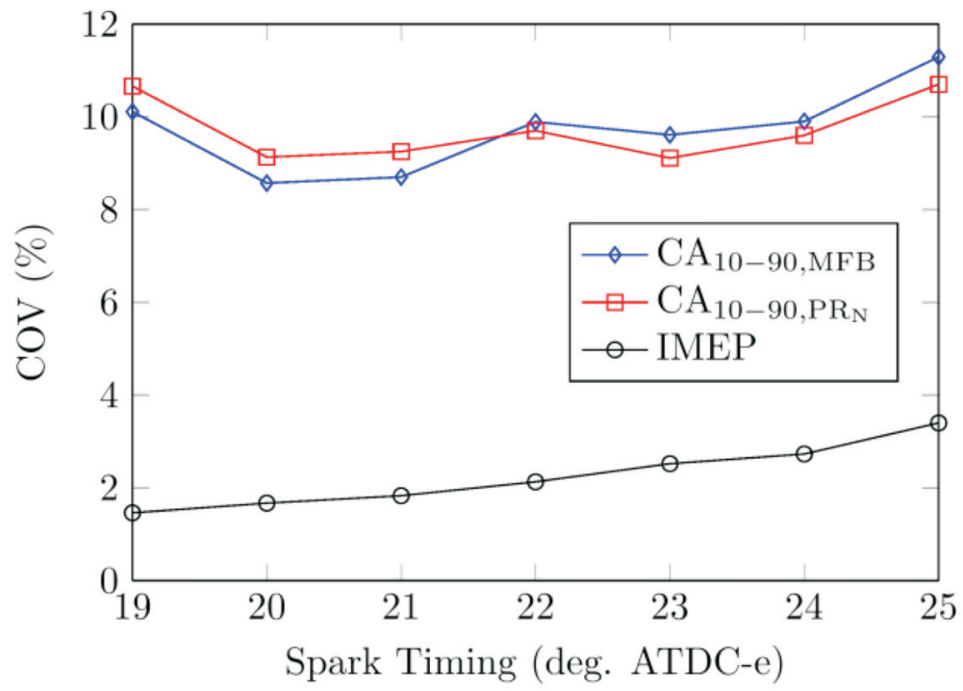

Air-fuel ratio effects - the effect of a lean air-fuel ratio on the rate of combustion was investigated by varying the equivalence ratio from stoichiometric to $\varnothing=0.81$. Figure 15 shows the $\mathrm{CA}_{0-10}$ and $\mathrm{CA}_{10-90}$ burn durations for an engine speed of $850 \mathrm{rpm}$, and spark timing ranging from 20-22 ${ }^{\circ} \mathrm{CA}$ ATDC-e. It can be seen that lean conditions down to $\varnothing=0.9$ exhibit no change in either the early flame development time $\left(\mathrm{CA}_{0-10}\right)$ or the main burn duration $\left(\mathrm{CA}_{10-90}\right)$. However, at $\varnothing=0.85$ and leaner, a parallel increase in the $\mathrm{CA}_{0-10}$ and $\mathrm{CA}_{10-90}$ burn durations is present. This is expected, given the reduced temperature under lean conditions and the dependence of laminar flame speed on temperature.

While the engine will run at equivalence ratios less than 0.8, misfires cause unstable exhaust $\mathrm{O}_{2}$ readings, which makes it difficult to determine

Fig. 14. Coefficient of variation for MFB, PRN, and IMEP as a function of spark timing 


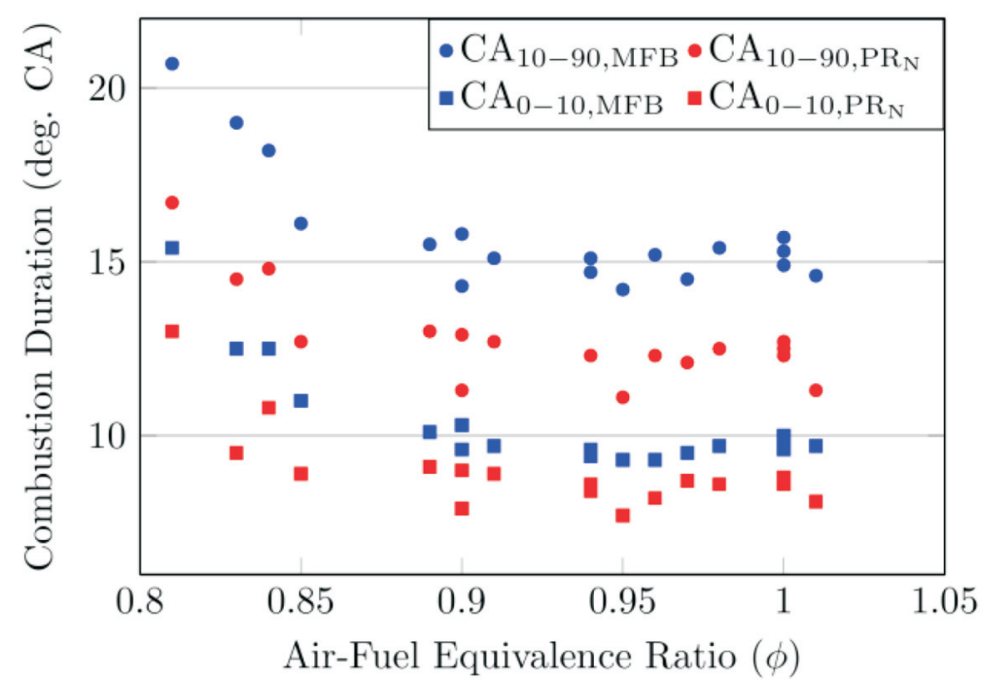

Fig. 15. Effect of air-fuel ratio on combustion duration; $850 \mathrm{rpm}$, WOT, 20-22 ${ }^{\circ}$ spark timing

the steady-state air-fuel ratio. It is worthwhile to note that none of the 300-cycle data sets shown in Fig. 15 contain any misfires.

As an assessment of stability, the COV of the $\mathrm{CA}_{10-90}$ burn duration, as well as IMEP, are shown in Fig. 16 as function of air-fuel ratio. Stability in both parameters are relatively constant between $\varnothing=0.9$ and 1 , with average COV values of 9.2 and $2.1 \%$, respectively. Charges leaner than $\varnothing=0.85$ depict a similar trend to Fig. 15, indicating larger cyclic variability under these conditions.

Discussion - overall, the data presented in this work shows the combustion duration in the split-cycle engine to be quicker than some CNG-fueled engines [1, 26], and on par with others $[8,10,27]$. However, the references used for comparison also have combustion phased much closer to TDC and therefore achieve greater peak cylinder pressures, resulting in higher gas temperatures and chemical reaction rates. This begs the question whether more advanced spark timing (closer to TDC) will continue to hasten combustion in the split-cycle engine. Trends in both the early flame development $\left(\mathrm{CA}_{0-10}\right)$ and main burn $\left(\mathrm{CA}_{10-90}\right)$ indicate this may in fact be the case, although current limitations of the crossover valve must be addressed in order to further investigate.

Despite the sonic flow condition of the charge as it enters the cylinder prior to combustion, and the presuming turbulence intensity, the cyclic variation of IMEP was lower than expected: ranging from approximately 1.5 to $3 \%$ for the majority of conditions tested, except at equivalence ratios leaner than $\varnothing=0.85$. This is a good indication that cylinder conditions at the time of spark, with respect to: local air-fuel ratio, charge homogeneity, state properties, and fluid motion, are relatively consistent. As spark timing is advanced closer to TDC the stability has shown to improve, however, it is anticipated that as the spark timing approaches the main flow period coming from the crossover passage, high strain rates and kernel convection caused by high bulk flow velocity may result in diminished stability.

\section{Conclusions}

1. The use of split-cycle engine architecture has been shown to provide rapid and stable combustion of methane fuel.

2. For the limited range of engine conditions tested, the normalized pressure ratio (PRN) is a good predictor of combustion progress in lieu of the regular mass fraction burn (MFB) calculation. This is especially helpful for cases when the crossover valve remains open during the early stages of combustion; the flow from which falsely manifests itself as combustion.

3. The main combustion duration has been found to be largely decoupled from the spark timing due to the independence of turbulence generation from piston motion. In other words, fast combustion was achieved without the use of intake stroke charge motion (tumble or swirl), piston squish, or a high mean piston speed.

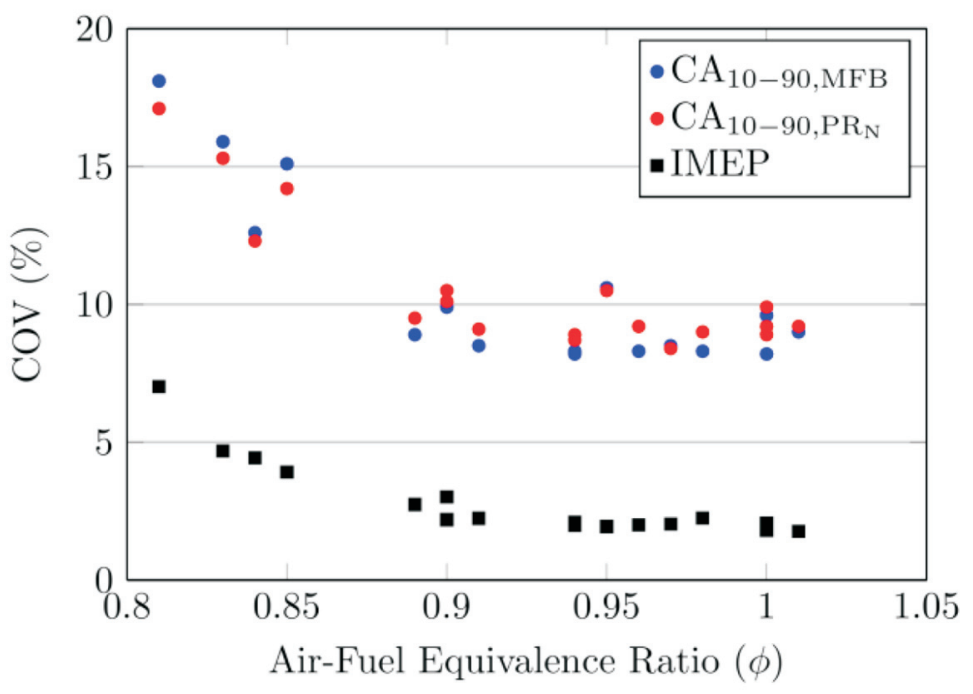

Fig. 16. Coefficient of variation for burn duration and IMEP as a function of air-fuel ratio; $850 \mathrm{rpm}$, WOT, $20-22^{\circ}$ spark timing

4. The burn duration and combustion stability were found to be non-responsive to lean air-fuel ratios in the range of $\varnothing=0.9$ to 1.0 . Variation in burn duration, and consequently IMEP, increases for mixtures leaner than 0.9.

\section{Future work}

The next steps into the split-cycle engine research will be focused on achieving earlier-phased combustion by increasing the crossover valve retention force, which will allow for higher peak cylinder pressures. Exhaust gas emissions and higher engine speeds will also be explored. 


\section{Nomenclature}

$\begin{array}{llll}\text { NG } & \text { Natural gas } & \text { CA }_{10-90} & \text { Crank angle duration of 0.1 to 0.9 MFB } \\ \text { HC } & \text { Hydrocarbons } & \text { IMEP } & \text { Indicated mean effective pressure } \\ \text { CO } & \text { Carbon monoxide } & \text { MFB } & \text { Mass fraction burned } \\ \text { OHC } & \text { Overhead camshaft } & \text { COV } & \text { Coefficient of variation } \\ \text { MBT } & \text { Maximum brake torque } & \text { ATDC-e } & \text { After TDC of expansion cylinder } \\ \text { XOVO } & \text { Crossover outlet valve opening } & \text { LPP } & \text { Location of peak pressure } \\ \text { XOVC } & \text { Crossover outlet valve closing } & \text { PRN } & \text { Normalized pressure ratio } \\ \text { SOC } & \text { Start of combustion } & \text { WOT } & \text { Wide open throttle } \\ \text { TDC } & \text { Top dead centre } & { }^{\circ} \text { CA } & \text { Degrees crank angle }\end{array}$

\section{Bibliography}

[1] Evans R.L., Blaszczyk J. A comparative study of the performance and exhaust emissions of a spark ignition engine fuelled by natural gas and gasoline. Proc. Inst. Mech. Eng. Part D, J. Automob. Eng., vol. 211, no. 1, pp. 39-47, Jan. 1997.

[2] Cho H.M., He B.-Q. Spark ignition natural gas engines - a review. Energy Convers. Manag., vol. 48(2), pp. 608-618, Feb. 2007.

[3] Semin R.A.B. A technical review of compressed natural gas as an alternative fuel for internal combustion engines. Am. J. Eng. Appl. Sci., vol. 1, no. 4, pp. 302-311, 2008.

[4] Korakianitis T., Namasivayam A.M., Crookes R.J. Naturalgas fueled spark-ignition (SI) and compression-ignition (CI) engine performance and emissions. Prog. Energy Combust. Sci., vol. 37(1), pp. 89-112, Feb. 2011.

[5] Johansson B., Olsson K. Combustion chambers for natural gas SI engines part I: fluid flow and combustion. SAE Tech. Pap. 950469, 1995.

[6] Hui X., Lapointe L.A. Combustion characteristics of lean burn and stoichiometric with EGR ignited natural gas engines. Proc. ASME 2014 Intern. Combust. Engine Div. Fall Tech. Conf., vol. ICEF2014, no. 5521, 2014.

[7] Das A., Watson H.C. Development of a natural gas spark ignition engine for optimum performance. Proc. Inst. Mech. Eng. Part D J. Automob. Eng., vol. 211, no. 5, pp. 361-378, Jan. 1997.

[8] Tunestål P., Christensen M., Einewall P., Andersson T., Johansson B., Jonsson O. Hydrogen addition for improved lean burn capability of slow and fast burning natural gas combustion chambers. SAE Tech. Pap. 2002-01-2686, 2002.

[9] Kastanis E., Evans R.L. The squish-jet combustion chamber for ultra-lean burn natural gas engines. SAE Tech. Pap. 201124-0112, 2011.

[10] Olsson K., Johansson B. Combustion chambers for natural gas SI engines part 2: combustion and emissions. SAE Tech. Pap. 950517, 1995.

[11] Ancimer R. The influence of in-cylinder flows on the flame kernel growth in natural gas fuelled spark ignition engines. University of Toronto, 2000.

[12] Musu E., Rossi R., Gentili R. Clean diesel combustion by means of the HCPC concept. SAE Tech. Pap. 2010-01-1256, 2010.

[13] Thurston K., Lundy J. Split-cycle engine and method of operation. US Patent 3,880,126, 1975.

Iain Cameron, $\mathrm{PhD}$. student at University of Windsor, Ontario, Canada.
[14] Phillips F., Gilbert I., Pirault J.P., Megel M. Scuderi split cycle research engine: overview, architecture and operation. SAE Tech. Pap., no. 2011-01-0403, 2011.

[15] Webb S.J., Webb R.D. Gas engine. US Patent 1,062,999, 1913.

[16] De Vries G. Internal combustion engine. US Patent 3,623,463, 1971.

[17] Tour B. Double piston cycle engine, US Patent 7,516,723, 2009.

[18] Scuderi S., Scuderi S. Split-cycle air hybrid engine. Patent, WO 2007/0814452007.

[19] Meldolesi R., Bailey G., Lacy C., Gilbert I., Pirault J.P., Perkins A. Scuderi split cycle fast acting valvetrain: architecture and development. SAE Tech. Pap., no. 2011-01-0404, 2011.

[20] Branyon D., Simpson D. Miller cycle application to the Scuderi split cycle engine (by downsizing the compressor cylinder). SAE Tech. Pap. 2012-01-04, 2012.

[21] Douailler B., Ravet F., Delpech V., D. Soleri, Reveille B., Kumar R. Direct injection of CNG on high compression ratio spark ignition engine: numerical and experimental investigation," SAE Tech. Pap. 2011-01-0923, 2011.

[22] Ball J.K., Raine R.R., Stone C.R. Combustion analysis and cycle-by-cycle variations in spark ignition engine combustion part 1: an evaluation of combustion analysis routines by reference to model data. Proc. Inst. Mech. Eng. Part D, vol. 212, no. D5, pp. 381-399, 1998.

[23] Eriksson L. Spark advance modeling and control. No. 580. p. $183,1999$.

[24] Hires S.D., Tabaczynski R.J., Novak J.M. The prediction of ignition delay and combustion intervals for a homogeneous charge, spark ignition engine. SAE Tech. Pap., pp. 1053-1067, 1979.

[25] Heywood J.B. Internal Combustion Engine Fundamentals. New York: McGraw-Hill, 1988.

[26] Ma F., Wang Y., Liu H., Li Y., Wang J., Zhao S. Experimental study on thermal efficiency and emission characteristics of a lean burn hydrogen enriched natural gas engine. Int. J. Hydrogen Energy, vol. 32, no. 18, pp. 5067-5075, Dec. 2007.

[27] Saanum I., Bysveen M., Tunestål P., Johansson B. Lean burn versus stoichiometric operation with EGR and 3-way catalyst of an engine fueled with natural gas and hydrogen enriched natural gas. SAE Tech. Pap., 2007.

Andrzej Sobiesiak, PhD., - Professor and Head, Department of Mechanical, Automotive and Materials Engineering, University of Windsor, Canada.

e-mail: asobies@uwindsor.ca

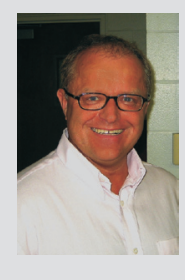

